\title{
Positron Lifetime Measurements of Subsurface Region in Aluminium Alloy and Aluminium Alloy Composite after Dry Sliding
}

\author{
E. DRYZEK \\ Institute of Nuclear Physics, Polish Academy of Sciences \\ Radzikowskiego 152, 31-342 Kraków, Poland
}

\begin{abstract}
This paper presents positron lifetime studies of the subsurface region of AK12 aluminium alloy and $\mathrm{Al}_{2} \mathrm{O}_{3}$-particle-reinforced $\mathrm{AK} 12$ aluminium alloy composite after sliding against steel in the pin-on-disc machine. The defect depth profile detected in the AK12 alloy extended up to $300 \mu \mathrm{m}$ but for the composite AK12 the range of this profile was significantly shortened to less than $\sim 90 \mu \mathrm{m}$. The positron lifetime dependence on depth evidences a steep gradient of defect concentration near the surface. The subsurface zones have been also examined using scanning electron microscopy.
\end{abstract}

PACS numbers: 78.70.Bj

\section{Introduction}

Wear is related to the removal of material from the solid surface as a result of e.g. sliding contact. This process may involve chemical dissolution or physical separation. Wear in most metallic alloys is controlled by plastic deformation of the material. In the classical adhesive wear model of Archard [1], based on a mechanism of adhesion at the asperities, the wear volume is proportional to the sliding distance and normal load applied on the contact surface and inversely proportional to the material hardness. Therefore enhanced wear resistance was associated with increase in hardness. The effect of the material's microstructure was ignored. Suh [2] proposed the delamination wear theory basing on a dislocation model to explain the deformation and fracture of surfaces in sliding contact. The surface layers are the subject of cyclic plastic deformation by normal and tangential loads. The movement of dislocations caused by sliding contact results not only 
in creation of dislocation pile-ups and nucleation of cracks or voids especially at inclusions or second phase particles in the plastically deformed subsurface zone but also produces defect distribution expanding deeper into the material. On the other hand, particles precipitated in the crystal lattice inhibit movement of dislocations and decrease the range of defect depth distribution. This type of defect depth distribution may be detected by positron annihilation spectroscopy as a method used for investigation of crystal lattice defects in metals and alloys. It is specifically sensitive to open volume defects such as vacancies, vacancy clusters or microvoids and to some extent dislocations. Our previous positron annihilation studies of subsurface region emerging in different processes of surface deformation such as sliding friction, indentation or compression were performed initially for pure metals like copper [3-5] and aluminium [6, 7]. Our studies of aluminium alloys [8-10] confirmed the influence of the precipitations on the defect depth profile generated in sliding contact. For example, the total range of the defect depth profile obtained for 2017 A aluminium alloy was $120 \mu \mathrm{m}$. This value may be compared with $400 \mu \mathrm{m}$ obtained for pure aluminium.

A microstructure of casting aluminium-silicon alloys with near-eutectic composition consists of hard silicon particles distributed in the $\mathrm{Al}$ matrix and differs from the microstructure of the wrought alloys with lower contents of alloying elements studied previously. In this case we expect the significant effect of hard precipitations on the expansion of defects depth profile generated in sliding process. This effect should be even more marked for metal matrix composite (MMC) constituted of aluminium alloy reinforced with ceramic particulates.

It has to be mentioned that the near-eutectic aluminium-silicon alloys and aluminium matrix composite materials fabricated by the addition of the reinforcement phase such as continuous boron or graphite fibres or hard particles, e.g. SiC and $\mathrm{Al}_{2} \mathrm{O}_{3}$, are important for engineering applications.

The paper reports the results of the positron lifetime measurements of casting aluminium alloy $\mathrm{AK} 12$ and aluminium alloy composite $\mathrm{AK} 12-\mathrm{Al}_{2} \mathrm{O}_{3}$ after dry sliding against steel. The objective is to investigate the influence of the ceramic reinforcement on the defect distribution in the subsurface region occurred during wear. The subsurface has been also examined using scanning electron microscopy.

\section{Experimental procedure}

The samples were machined from the commercial aluminium cast alloy AK12 (with the following composition: Si 12.0-13.5 wt.\%, Cu 0.5-1.5 wt.\%, Mg 1.0-1.5 wt.\%, Ni 0.5-1.5 wt.\%, Mn 0.2 wt.\%, Zn 0.2 wt.\%, Fe 0.6 wt.\%, $\mathrm{Al}$ balance) and composite $\mathrm{AK} 12$ with $(15 \pm 4)$ vol. $\%$ of $\mathrm{Al}_{2} \mathrm{O}_{3}$ in the form of cylinders $15 \mathrm{~mm}$ high and $10 \mathrm{~mm}$ in diameter. The specimens were heat treated $\left(515^{\circ} \mathrm{C}\right.$ for $6 \mathrm{~h}$, warm water quenching $60^{\circ} \mathrm{C}$, ageing at $175^{\circ} \mathrm{C}$ for $\left.16 \mathrm{~h}\right)$. In the case of composite the volume fraction of reinforcement was quantified from the density of material. 
The dry sliding tests were carried out in the pin-on-disk apparatus in air at room temperature. The cylinder was a pin which was sliding against a disk of diameter $50 \mathrm{~mm}$ made from the steel SW18. The sliding velocity of $50 \mathrm{~mm} / \mathrm{s}$ was maintained during the test. The tests were carried out with the load $106 \mathrm{~N}$ for two different sliding distances: $6.3 \mathrm{~m}$ and $252 \mathrm{~m}$. The base surfaces of two cylinders treated in an identical procedure were sandwiched with the $7 \mu \mathrm{m}$ thick kapton envelope which contains the positron emitter ${ }^{22} \mathrm{Na}$ of $38 \mu \mathrm{Ci}$ activity.

The positron lifetime spectra were measured using the conventional fast-fast spectrometer with $\mathrm{BaF}_{2}$ scintillators. The time resolution of the system was $240 \mathrm{ps}$ (FWHM). All obtained spectra containing $\sim 2 \times 10^{6}$ counts were deconvoluted using the LT code subtracting the background and the source component [11]. The positrons emitted from the ${ }^{22} \mathrm{Na}$ source have sufficient energy $\left(E_{\max }=544 \mathrm{keV}\right)$ to penetrate a certain depth of the specimen. The implantation profile of positrons from the radioactive source can be described by exponential decay function characterised by the linear absorption coefficient of positrons in matter $\alpha_{+}$, which depends for example on matter density and maximum positron energy $E_{\max }$ [12]. The measured $S$-parameter or mean positron lifetime depth profiles are convolutions of the positron implantation profile and the actual $S$-parameter or mean positron lifetime depth profiles [13]. In the case of aluminum the mean penetration depth of positrons from ${ }^{22} \mathrm{Na}$ source equal to the reciprocal of $\alpha_{+}$is equal to $94.2 \mu \mathrm{m}$. It means that $\sim 63.8 \%$ of positrons are stopped to this depth and annihilate contributing mainly to the obtained value of the positron lifetime. Thus in our measurements we ignore the near surface gradients and near surface mixing and oxide effects. The depth resolution of the method in the case of aluminum seems to be much lower than in the case of copper for which the corresponding value is equal to $28 \mu \mathrm{m}$. At this stage it is difficult to deconvolute the obtained experimental dependences.

In order to obtain the defect profile in the subsurface zones the subsequent measurements of the positron lifetime spectrum after removing a layer of thickness of $30 \mu \mathrm{m}$ were performed. The layers were removed by grinding using $\mathrm{SiC}$ pastes on a thick iron plate. The removed layer thickness is referred to as a depth from the surface exposed to sliding. The grinding process may induce some additional defects in the layer very close to the surface whose thickness is much smaller than the positron implantation range in aluminium. Assuming that the contribution to the positron lifetime spectrum coming from these defects is small and its magnitude is similar for each measurement, changes in the positron lifetime spectra can be attributed to sliding.

A specific wear rate (the worn volume per unit sliding distance per unit load) was calculated from the weight loss measured for sliding distances: $63 \mathrm{~m}, 126 \mathrm{~m}$, $189 \mathrm{~m}$, and $252 \mathrm{~m}$. The subsurface of the samples was studied using scanning electron microscope (SEM). The sectioning was done normal to the worn surface with a low speed diamond saw and the specimens were polished. 


\section{Results and discussion}

The specific wear rates determined for the AK12 alloy and the MMC for the load of $106 \mathrm{~N}$ are equal to $0.66 \times 10^{-13} \mathrm{~m}^{3} /(\mathrm{m} \mathrm{N})$ and $1.32 \times 10^{-13} \mathrm{~m}^{3} /(\mathrm{m} \mathrm{N})$, respectively. The value for the AK12 alloy is comparable with the specific wear rate obtained by Somi Reddy et al. [14] for Al-Si binary alloys in the mild wear region.

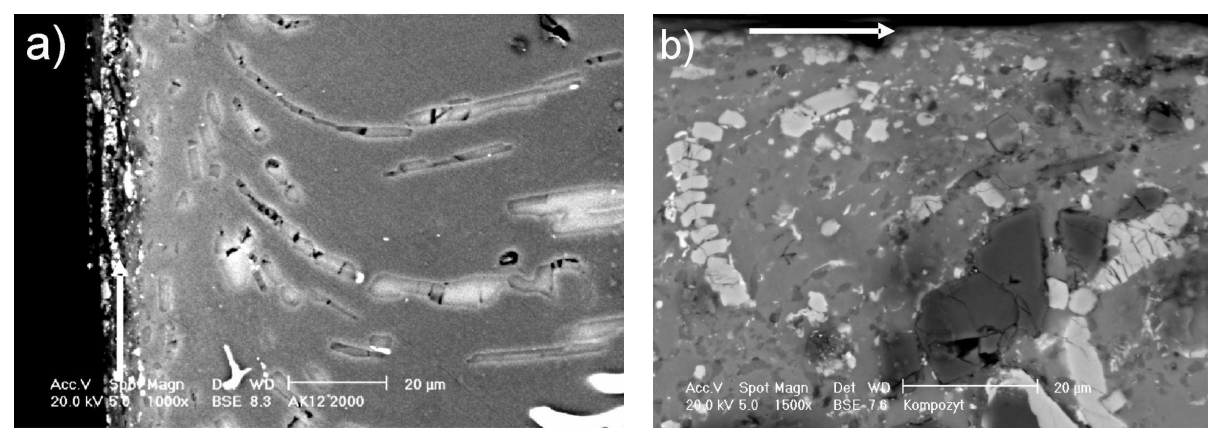

Fig. 1. Scanning electron micrographs of subsurfaces of AK12 alloy (a) and composite $\mathrm{AK} 12-\mathrm{Al}_{2} \mathrm{O}_{3}$ (b) showing besides particles of precipitates rich in Si (bright) also particles of $\mathrm{Al}_{2} \mathrm{O}_{3}$ (dark grey) after sliding at the normal load of $106 \mathrm{~N}$ for the distance of $252 \mathrm{~m}$. Arrows indicate the sliding direction.

Figure 1 presents the SEM micrographs of the AK12 alloy (a) and the MMC (b) subsurface after sliding. The view of the AK12 subsurface reveals fragmented particles of precipitates rich in $\mathrm{Si}$ but the range of its occurrence is less than $50 \mu \mathrm{m}$. Within the subsurface band of $20 \mu \mathrm{m}$ fragments of the silicon particles have a size from $1 \mu \mathrm{m}$ to a few micrometers. Even the application of a higher load in the case of binary $\mathrm{Al}-13 \% \mathrm{Si}$ alloy reported in [14], which leads to severe wear or seizure, gave the changes in microstructure to a depth of $75 \mu \mathrm{m}$. The SEM micrograph of the MMC subsurface shows fragmented both: precipitates rich in $\mathrm{Si}$ and particles of $\mathrm{Al}_{2} \mathrm{O}_{3}$. The range of its occurrence is comparable to that in AK12 alloy. The presence of $\mathrm{Al}_{2} \mathrm{O}_{3}$ particles may limit the degree of surface flow. However, the $\mathrm{Al}_{2} \mathrm{O}_{3}$ particles are not considered as bearing the load and preventing surface plastic flow. The fracture and re-embedding of $\mathrm{Al}_{2} \mathrm{O}_{3}$ particles have been reported in the literature $[15,16]$. Undoubtedly, in the case of studied MMC the total volume fraction of hard particles is higher than in AK12 alloy.

In the positron lifetime spectra measured for the AK12 alloy a single component was sufficient to obtain a satisfactory fit. Such single component spectra were observed for the $\mathrm{Al}-\mathrm{Cu}-\mathrm{Mg}$ alloys [17], which was interpreted as an outcome of competitive trapping in different families of defects giving lifetimes too close to be isolated. Only mean lifetime was considered also by Petersen [18] for the aluminium single-crystal deformed $50 \%$ by rolling. In that case the different positron 
traps in the specimen were confirmed by the electron microscope examination which revealed the presence of vacancy loops with a size distribution. In our case the variety of positron trapping sites arises as well from the microstructure, i.e. the presence of precipitates in the alloy as from the plastic deformation of the subsurface during sliding.

In the case of the MMC single component fits done on a trial basis were not satisfying. Fitting two lifetime components to the obtained spectra we decided to fix the value of the first component equal to 155 ps. Intensity of this component was close to $20 \%$ for all spectra. In the literature, there is reported the value of the mean positron lifetime in $\mathrm{Al}_{2} \mathrm{O}_{3}$ at room temperature equal to $150 \mathrm{ps}$ [19] and earlier results for polycrystalline $\mathrm{Al}_{2} \mathrm{O}_{3}$ with two components of positron lifetime e.g. $\tau_{1}=159 \pm 8 \mathrm{ps}, \tau_{2}=720 \pm 30 \mathrm{ps}, I_{2}=2.2 \%$ [20]. The intensity ratio $I_{2} / I_{1}$ is close to 0.25 which exceeds the ratio of the volume fractions of reinforcement particles and the matrix alloy equal to 0.18 . The difference may be caused by error of density estimation and the reinforcement volume fraction may be higher than $15 \%$. Te second lifetime component could represent positron annihilation in the matrix alloy and corresponds to the single component in the AK12 lifetime spectrum will be referred to as the lifetime in the matrix alloy.

Figure 2a presents the dependences of the positron lifetime on depth for the AK12 alloy samples after sliding with the load of $106 \mathrm{~N}$. For the sliding distance of $6.3 \mathrm{~m}$ changes of the positron lifetime with depth are negligible and its value does not depart much from the $\sim 222$ ps assumed as the bulk value.

For the sliding distance of $252 \mathrm{~m}$ the value of the positron lifetime measured at the surface is equal to $\sim 238$ ps and exhibits approximately an exponential decay with the depth described by the following formula:

$$
\tau=\tau_{0}+A \exp \left(-d / d_{0}\right),
$$

where $d$ is the depth. Such a function has been found in our former studies and it seems to be a common feature for the subsurface zones created during the sliding process and detected by positron annihilation spectroscopy. The dashed line in Fig. 1a presents the best fit of Eq. (1) to the experimental points. The values of the obtained parameters are given in the Table. The deviation of the experimental points from the exponential decay for the depth of $270 \mu \mathrm{m}$ and $300 \mu \mathrm{m}$ may suggest the presence of a layer with higher concentrations of defects.

The total range of the positron lifetime changes is $330 \mu \mathrm{m}$. It is much deeper than $120 \mu \mathrm{m}$ in the $2017 \mathrm{~A}$ alloy for the sliding distance of $126 \mathrm{~m}$ [10] but it is more shallow than in pure aluminium [7]. The obtained dependence of the positron lifetime on depth corresponding to the defect depth distribution reveals information on changes caused by sliding (at the level of crystal lattice) whose total range is much larger than the range of microstructure changes in the subsurface observed using SEM. 


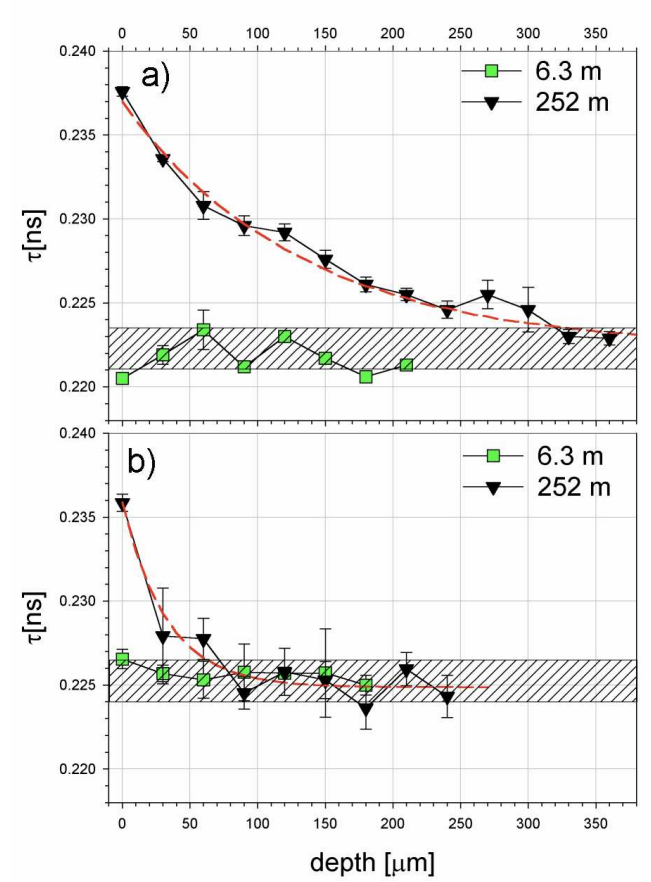

Fig. 2. The positron lifetime as a function of the depth measured for the specimens of the AK12 alloy (a) and composite $\mathrm{AK}_{12}-\mathrm{Al}_{2} \mathrm{O}_{3}$ (b) which were treated in the sliding experiment for the distances of $6.3 \mathrm{~m}$ and $252 \mathrm{~m}$ at the normal load of $106 \mathrm{~N}$. The dashed lines are the best fits of the relation (1) to the experimental points for the distance of $252 \mathrm{~m}$. The shaded areas mark the bulk values of the positron lifetime.

\section{TABLE}

The values of parameters of the formula (1) fitted to the experimental dependence of the positron lifetime on depth.

\begin{tabular}{c|c|c|c}
\hline \hline & $\tau_{0}(\mathrm{~ns})$ & $A(\mathrm{~ns})$ & $d_{0}(\mu \mathrm{m})$ \\
\hline AK12 & $0.2223 \pm 0.0007$ & $0.0147 \pm 0.0006$ & $132 \pm 17$ \\
MMC & $0.2248 \pm 0.0005$ & $0.0110 \pm 0.0007$ & $33 \pm 11$
\end{tabular}

Figure $2 \mathrm{~b}$ shows the dependences of the second positron lifetime component on depth for the MMC samples after sliding in the identical condition as above for AK12 alloy. As with the AK12 alloy for the sliding distance of $6.3 \mathrm{~m}$ the positron lifetime changes with depth are negligible but the value assumed as the bulk lifetime in matrix alloy equal to $\sim 225 \mathrm{ps}$ is slightly higher than in the AK12 alloy. It may be caused by the differences in microstructure of the matrix in the MMC and the alloy or the contribution of the positron annihilation in the interface 
between reinforcement particles and composite matrix. Influence of the lifetime component separation procedure cannot be excluded in this case but the changes of $\tau_{2}$ or mean lifetime $\left(\bar{\tau}=I_{1} \tau_{1}+I_{2} \tau_{2}\right)$ are essential. The value of the second lifetime component at the surface is equal to $236 \mathrm{ps}$, which is slightly lower than the positron lifetime in AK alloy, and decreases sharply with the depth. It implies a much smaller total range of the positron lifetime changes which for the MMC is $c a$. $90 \mu \mathrm{m}$. It is more than three times lower than for the AK12 alloy sample treated in the same way in the pin-on-disk. As in the case of AK12 the exponential decay function can be also fitted to the experimental points. However the obtained value of the $d_{0}$ parameter given in the Table is four times smaller than that for AK12. Such a positron lifetime dependence on depth evidences a steep gradient of defect concentration near the surface. This steep gradient of defect concentration and a higher wear rate suggest that in the case of the MMC during sliding the energy is deposited to a higher degree in the regions close to the surface. Therefore, the hard particles of the reinforcement prevent dislocation movement inside the material. In practical applications one should find the optimum kind, concentration and size of reinforcement particles to allow defects to deeper penetrate during sliding without deterioration of other properties of composite material.

\section{Conclusions}

Positron annihilation studies gave quantitative information about the total range of the subsurface zones created in the sliding process of AK12 aluminium alloy and aluminium alloy composite $\mathrm{AK} 12-\mathrm{Al}_{2} \mathrm{O}_{3}$ including the zone deformed elastically. This type of quantitative information at the level of crystal lattice defect size cannot be obtained from the SEM micrographs which show the changes of the microstructure. The range of microstructure changes caused by sliding in the case of the AK12 alloy is much shallow than defect depth profile. However in the case of MMC the difference is significantly smaller. For the studied MMC the presence of the hard particles of $\mathrm{Al}_{2} \mathrm{O}_{3}$ reinforcement reduces the total depth of the subsurface zones however causes the increase in wear rate which is disadvantageous from the practical point of view.

In order to broaden the range of positron annihilation application in material science it would be interesting to compare the defect depth profile obtained using the positron annihilation method with the microhardness profile. The changes of microhardness, e.g. hardening or softening of the material, are related to some degree to the concentration of dislocations while positron annihilation is sensitive mainly to the point defects.

\section{Acknowledgment}

The author expresses her gratitude to the State Committee for Scientific Research (Poland) which supports this work by grant No. 2 P03B 008 24. The 
author would like to thank prof. J. Śleziona (Faculty of Materials Science and Metallurgy, The Silesian University of Technology) for providing the samples of aluminium alloy composite.

\section{References}

[1] J.F. Archard, J. Appl. Phys. 24, 981 (1953).

[2] N.P. Suh, Wear 25, 111 (1973).

[3] J. Dryzek, E. Dryzek, T. Stegemann, B. Cleff, Tribology Lett. 3, 269 (1997).

[4] J. Dryzek, E. Dryzek, Börner, R. Krause-Rehberg, Tribology Lett. 11, 29 (2001).

[5] J. Dryzek, E. Dryzek, Tribology Lett. 15, 309 (2003).

[6] J. Dryzek, E. Dryzek, Mater. Sci. Forum 445-446, 72 (2004).

[7] J. Dryzek, E. Dryzek, Tribology Lett. 17, 147 (2004).

[8] E. Dryzek, J. Mater. Sci. 38, 3755 (2003).

[9] J. Dryzek, E. Dryzek, submitted to Tribology Int.

[10] E. Dryzek, J. Dryzek, submitted to Tribology Int.

[11] J. Kansy, Nucl. Instrum. Methods A 374, 235 (1996).

[12] G.I. Gleason, I.D. Taylor, D.I. Tabern, Nucleonics 8, 12 (1951).

[13] J. Dryzek, Nukleonika 42, 95 (1997).

[14] A. Somi Reddy, B.N. Pramila Bai, K.S.S. Murthy, S.K. Biswas, Wear 171, 115 (1994).

[15] J. Zhang, A.T. Alpas, Mater. Sci. Eng. A 161, 273 (1993).

[16] M. Narayan, M.K. Surappa, B.N. Pramila Bai, Wear 181-183, 563 (1995).

[17] A. Somoza, A. Dupasquier, I.J. Polmear, P. Folegati, R. Ferragut, Phys. Rev. B 61, 14454 (2000).

[18] K. Petersen, in: Positron Solid-State Physics, Ed. W. Brandt, North Holland Publ. Company, Amsterdam 1983, p. 298.

[19] M. Forster, W. Claudy, H. Hermes, M. Koch, K. Maier, J. Major, H. Stoll, H.-E. Schaefer, Mater. Sci. Forum 105-110, 1005 (1992).

[20] M. Noguchi, T. Mitsuhashi, T. Chiba, T. Tanaka, N. Tsuda, J. Phys. Soc. Jpn. 32, 1242 (1972). 